Tropical Journal of Pharmaceutical Research April 2016; 15 (4): 885-889

ISSN: $1596-5996$ (print); 1596-9827 (electronic)

(C) Pharmacotherapy Group, Faculty of Pharmacy, University of Benin, Benin City, 300001 Nigeria.

All rights reserved.

Available online at http://www.tjpr.org

Review Article

http://dx.doi.org/10.4314/tjpr.v15i4.31

\title{
Autophagy in photodynamic therapy
}

\author{
Liming Liang, Wenxiang Bi and Yuanyuan Tian* \\ Department of Biochemistry and Molecular Biology, School of Medicine, Shandong University, Jinan 250012, China \\ *For correspondence: Email: tianyuan@sdu.edu.cn; Tel: +86 53188382092
}

Received: 9 October 2015

Revised accepted: 11 March 2016

\begin{abstract}
Macroautophagy (autophagy) is crucial for cell survival during starvation and plays important roles in human diseases. It is a highly conserved intracellular degradation system in eukaryotes for removal and recycling of cytoplasmic components including damaged proteins and organelles to obtain energy. The relationship between cancer and autophagy has been extensively studied in recent years. In cancer and cancer therapy, autophagy acts as a double-edged sword. Photodynamic therapy (PDT) is a kind of tumor therapy applied with a tumor-localizing photosensitizing agent which is followed by activation with the light of a specific wavelength. How much is autophagy involved in photodynamic therapy? The work in this area is still limited.
\end{abstract}

Keywords: Autophagy, Photodynamic therapy, Apoptosis, Cancer

Tropical Journal of Pharmaceutical Research is indexed by Science Citation Index (SciSearch), Scopus, International Pharmaceutical Abstract, Chemical Abstracts, Embase, Index Copernicus, EBSCO, African Index Medicus, JournalSeek, Journal Citation Reports/Science Edition, Directory of Open Access Journals (DOAJ), African Journal Online, Bioline International, Open-J-Gate and Pharmacy Abstracts

\section{INTRODUCTION}

Autophagy is a conserved intracellular degradation process in which cellular organelles, proteins and invading microbes are degraded by lysosomes. There are three types of autophagy: macroautophagy, mitoautophagy and chaperonemediated autophagy. This review is focused on macroautophagy which is referred to as autophagy hereafter. It is induced by inactivation of mTOR complex 1 (mTORC1) and regulated by a series of Atg proteins. It performs double roles: promotes cell survival or cell death, also in cancer therapies [1].

Activation of autophagy is found in some human primary tumors. Autophagy protects cells against shortage of nutrients. The amino acids and fatty acids produced by autophagic degradation are used to generate ATP to help cancer cells to survive in an unfavorable starved environment [2].

\section{APOPTOSIS AND AUTOPHAGY}

Apoptosis is an energy dependent cellprogrammed death process in nucleated cells. Apoptosis, different from cell necrosis that is accompanied with severe irreversible injury, means a selective removal of individuals without complete disruption of the tissue. Apoptosis is recognized as an important cellular event during both normal development and disease progression [3,4]. During apoptosis, the intracellular content is wrapped in a small bubble of the membrane and swallowed by phagocyte and it is harmless to the surrounding cells. Apoptosis possesses unique morphologic features such as intact karyotheca, condensed nuclear chromatin attached to the karyotheca, wide perinuclear spaces, swollen mitochondria, formation of apoptotic bodies and cell shrinkage $[5,6]$. 
Caspases are responsible for many of the biochemical and morphological changes associated with apoptosis. Pathways for induction of apoptosis have been identifiedintrinsic and extrinsic, one involving caspase-8 and the other involving Caspase-9 as the most apical caspase, which can activate effector caspase, such as Caspase-3, -6, -7. The effector caspases then cleave intracellular substrates, thereby important cellular processes are disabled and eventually cell death is caused [7-9].

Autophagy is another kind of programmed cell death in addition to apoptosis. It is a selfdegradative catabolic process by which cells digest themselves. Autophagy is a fundamental function of eukaryotic cells and is well conserved from yeast to humans. The most typical trigger of autophagy is nutrient starvation; in this sense, lack of any type of essential nutrient can induce autophagy. In yeast, nitrogen starvation is the most potent stimulus [10].

Autophagosomes are double-membrane cytoplasmic vesicles that can engulf various cellular constituents, and then autophagosomes fuse with lysosomes to form autolysosomes, where sequestered cellular components are digested [11].

The autophagosomes are usually ultrastructures visualized by transmission electron microscope (TEM), and so it is a gold-standard method for determination of autophagy [12]. Although TEM has been the gold standard, this method requires considerable skills. Recent studies of autophagy have been expanded to the marker proteins of autophagy, and the molecular mechanism is now well understood.

\section{mTOR, Atg proteins and LC3}

Recent research has revealed roles of the protein kinase termed 'the target of rapamycin' (TOR) in autophagy. The mammalian target of rapamycin, mTOR, interacts with other proteins to form two main types of complex, mTOR complexes 1 and 2 (mTORC1 and mTORC2) [13], which can regulate autophagy negatively. In yeast, 31 autophagy-related (Atg) proteins have been identified, and many of them gather at a site that can be identified by fluorescence microscopy [10,14]. In mammalian, Beclin-1 and light chain 3 (LC3) are homologous proteins of Atg6 and Atg8 protein. Classical autophagy initiation begins with the complex involving Beclin-1. It is now widely known that microtubuleassociated protein LC3 is related to autophagy monitoring. The conversion of LC3-I to LC3-II is indicative of autophagic activity.

\section{Atg12-Atg5 complex}

Atg12 is conjugated to Atg5, catalyzed by two enzymes, Atg7 and Atg10. In this process, Atg proteins are modified and catalyzed in a ubiqutinlike way. Then Atg12-Atg5 conjugate associate with Atg16 and this contributes to bring LC3-II and phosphatidylethanolamine (PE) together to form LC3-II-PE complex (Fig 1) [15].

\section{Formation of LC3-II}

Pro-LC3 is turned into LC3-I catalyzed by Atg4 and Atg7, and then LC3-II-PE complex is formed catalyzed by Atg3, Atg12-Atg5 complex, finally free LC3-II is released (Fig 1) [16]. Soluble LC3-I and lipid bound LC3-II are associated with the formation of autophagosomes.

(a)

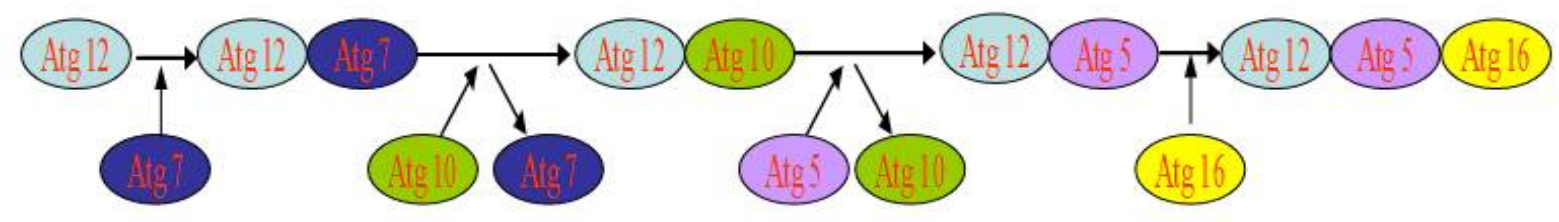

(b)

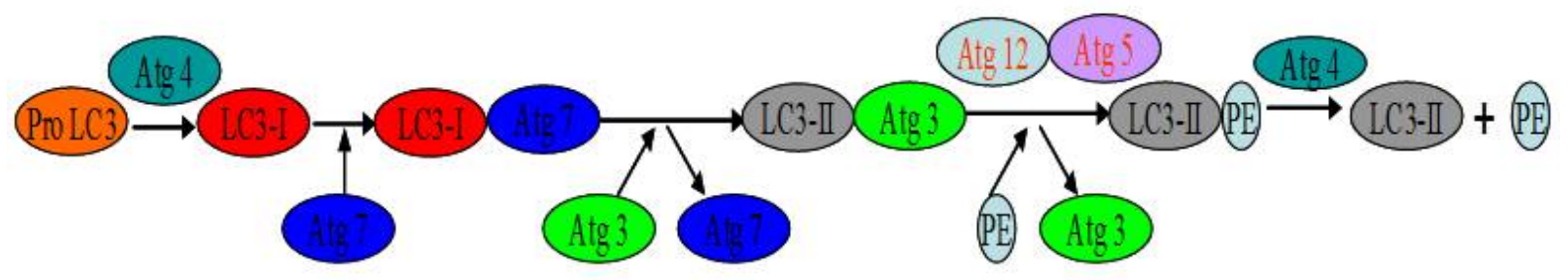

Figure 1: (a) Formation of Atg12-Atg5 complex. (b) Formation of LC3-II-PE complex 


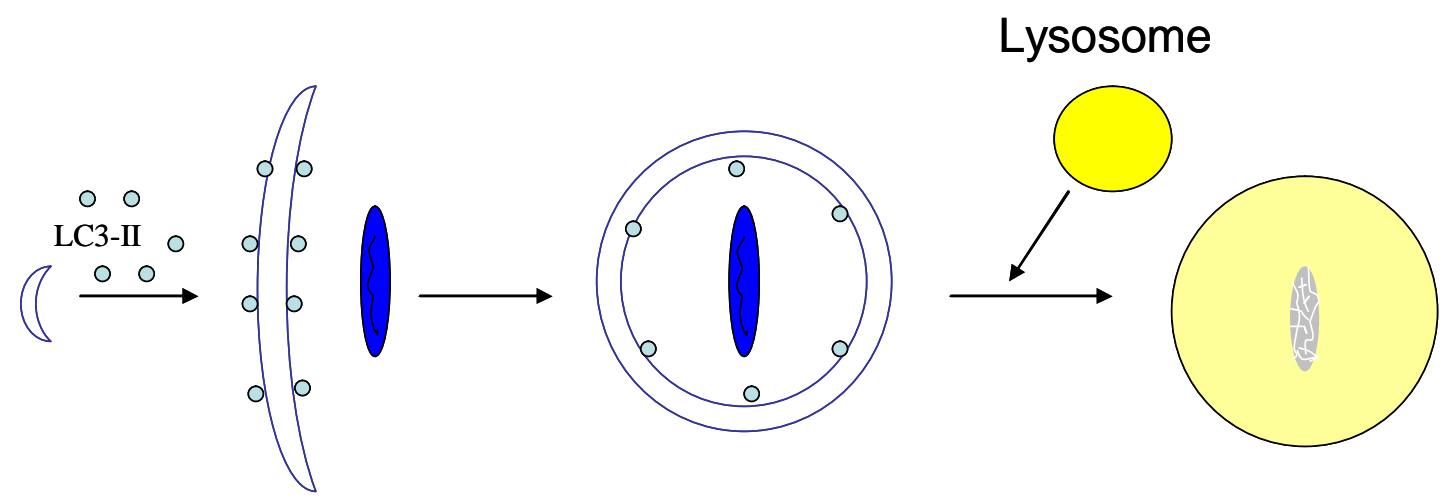

\section{Phagophore}

Figure 2: Process of autophagy

\section{Process of autophagy}

In the initial stage, the autophagosome, a double-membrane vesicle, arises from a membrane structure named phagophore which extends and sequesters cytoplasmic organelles such as mitochondria, endoplasmic reticulum and ribosomes, and then the edges of the membrane fuse to form the spherical structure, autophagosome. After fusing with lysosomes, the inner membrane and the engulfed components of the autophagosome are degraded by lysosome, forming a single-membrane vacuole structure called autolysosome (Fig 2) [17,18].

\section{Cell death in photodynamic therapy}

Photodynamic therapy can induce apoptosis, necrosis and autophagy, which is affected by many factors, such as the types of photosensitizers, cells and photodynamic dosage. The porphyrin family molecules, such as 5-ALA which localize in the mitochondria induce generation of reactive oxygen species (ROS) $[19,20]$ and mainly result in mitochondrial apoptosis involving activation of caspase cascades after photoactivation [21]. Autophagy is detected following PDT mediated by photosensitizers targeted at endoplasmic reticulum [22-24], mitochondria [25,26] or both endoplasmic reticulum and mitochondria [27].

Sasnauskiene's studies of Safr-mediated PDT on A-431 cells revealed that damage to mitochondrial interior at low and intermediate photodynamic dosages did not result in apoptosis; it induced autophagy in cells. However, when treated with a higher photodynamic dosage, extensive apoptosis appeared besides autophagy [28]. Kessel et al recently reported that $\mathrm{L} 1210$ cells underwent both autophagy and apoptosis following PDT with the endoplasmic reticulum sensitizer CPO, similar processes occurred in L1210 cultures following PDT with the mitochondrial sensitizer MC [29]. Recent observation of Francois et al demonstrated that cells submitted to the lowest PDT-dose displayed significant LC3-II expression, but there was no pronounced cyt C release and caspase cleavage [30].

Due to the high reactivity of photogenerated ROS [31-33], autophagy is initiated to remove oxidatively damaged organelles, such as mitochondria and endoplasmic reticulum which are targets of the photosensitizers [21,34,35]. Previous findings reflect that autophagy contributes to cell survival; in addition, antitumorigenic roles of autophagy are also mentioned in some research. A combination of autophagy inhibitor with PDT could promote apoptotic death, thus enhancing the treatment effect [36]. Therefore, autophagy can protect cells and help them to tolerate photodynamic therapy; however, if there is a high level of autophagy, it will lead to cell death.

\section{ACKNOWLEDGEMENT}

This work was supported by National Natural Science Foundation of China (no. 81401495).

\section{REFERENCES}

1. Zhirnov OP, Klenk HD. Influenza $A$ virus proteins NS1 and hemagglutinin along with $M 2$ are involved in stimulation of autophagy in infected cells. J Virol 2013; 87: 13107-13114. 
2. Hou $Y$, Dong $L W$, Tan $Y X$, Yang GZ, Pan YF, Li Z, Tang $L$, Wang $M$, Wang $Q$, Wang $H Y$. Inhibition of active autophagy induces apoptosis and increases chemosensitivity in cholangiocarcinoma. Lab Invest 2011; 91: 1146-1157.

3. Amir Gharib, Zohreh Faezizadeh, Masoud Godarzee. Preparation and characterization of nanoliposomal betacryptoxanthin and its effect on proliferation and apoptosis in human leukemia cell line K562. Trop J Pharm Res 2015; 14: 187-194.

4. Gurpinar E, Grizzle WE, Piazza GA. NSAIDs inhibit tumorigenesis, but how? Clin Cancer Res 2014; 20 : 1104-1113.

5. Tian Y, Leung W, Yue K, Mak N. Cell death induced by $M P P a-P D T$ in prostate carcinoma in vitro and in vivo. Biochem Biophys Res Commun 2006; 348: 413-420.

6. Tian $Y$, Kong $F$, Tian $X$, Guo $Q$, Cui $F$. Investigation of photodynamic effect caused by MPPa-PDT on breast cancer. Laser Phys Lett 2012; 5: 754-758.

7. Shen S, Zhang Y, Zhang R, Gong X. Sarsasapogenin induces apoptosis via the reactive oxygen speciesmediated mitochondrial pathway and ER stress pathway in HeLa cells. Biochem Biophys Res Commun 2013; 441: 519-524.

8. Shi $X$, Chen $X$, Li X, Lan X, Zhao C, Liu S, Huang H, Liu $N$, Liao $S$, Song $W$, Zhou $P$, Wang $S$, Xu L, Wang $X$, Dou QP, Liu J. Gambogic acid induces apoptosis in imatinib-resistant chronic myeloid leukemia cells via inducing proteasome inhibition and caspase-dependent Bcr-Abl downregulation. Clin Cancer Res 2014; 20: 151163.

9. Jiang $Z$, Chen $W$, Yan $X, B i$, Guo S, Zhan $Z$. Paeoniflorin protects cells from GalN/TNF- $\alpha$-induced apoptosis via ER stress and mitochondria-dependent pathways in human L02 hepatocytes. Acta Biochim Biophys Sin 2014; 46: 357-367.

10. Mizushima N. Autophagy: process and function. Genes Dev 2007; 21: 2861-2873.

11. Peng $W$, Du T, Zhang $Z$, Du F, Jin J, Gong A. Knockdown of autophagy-related gene LC3 enhances the sensitivity of HepG2 cells to epirubicin. Exp Ther Med 2015; 9: 1271-1276.

12. Roy R, Kumar D, Chakraborty B, Chowdhury C, Das P. Apoptotic and autophagic effects of Sesbania grandiflora flowers in human leukemic cells. PLoS One 2013; 8: e71672.

13. Han C. Dan, Aaron Ebbs, Manolis Pasparakis, Terry Van Dyke, Daniela S. Basseres, Albert S. Baldwin. Aktdependent Activation of mTORC1 Complex Involves Phosphorylation of mTOR (Mammalian Target of Rapamycin) by IKB Kinase a (IKKa). J Biol Chem 2014; 289: 25227-25240.

14. Kitamura K, Kishi-ltakura C, Tsuboi T, Sato S, Kita K, Ohta N, Mizushima N. Autophagy-related Atg8 localizes to the apicoplast of the human malaria parasite Plasmodium falciparum. PLoS One 2012; 7: e42977.
15. Yao H, Zhao D, Khan SH, Yang L. Role of autophagy in prion protein-induced neurodegenerative diseases. Acta Biochim Biophys Sin 2013; 45: 494-502.

16. Longatti A, Lamb CA, Razi M, Yoshimura S, Barr FA, Tooze SA. TBC1D14 regulates autophagosome formation via Rab11- and ULK1-positive recycling endosomes. J Cell Biol 2012; 197: 659-675.

17. Klionsky DJ, Eskelinen EL, Deretic V. Autophagosomes, phagosomes, autolysosomes, phagolysosomes, autophagolysosomes... wait, I'm confused. Autophagy 2014; 10: 549-551.

18. Tsuchihara K, Fujii S, Esumi H. Autophagy and cancer: dynamism of the metabolism of tumor cells and tissues. Cancer Lett 2009; 278: 130-138.

19. Valentine RM, Wood K, Brown CT, Ibbotson SH, Moseley $H$. Monte Carlo simulations for optimal light delivery in photodynamic therapy of non-melanoma skin cancer. Phys Med Biol 2012; 57: 6327-6345.

20. Kastle M, Grimm S, Nagel R, Breusing N, Grune $T$. Combination of PDT and inhibitor treatment affects melanoma cells and spares keratinocytes. Free Radic Biol Med 2011; 50: 305-312.

21. Sparsa $A$, Bellaton $S$, Naves $T$, Jauberteau $M O$, Bonnetblanc JM, Sol V, Verdier $M$, Ratinaud $M H$. Photodynamic treatment induces cell death by apoptosis or autophagy depending on the melanin content in two B16 melanoma cell lines. Oncol Rep 2013; 29: 11962000.

22. Garg AD, Dudek AM, Agostinis P. Autophagy-dependent suppression of cancer immunogenicity and effector mechanisms of innate and adaptive immunity. Oncoimmunol 2013; 2: e26260.

23. Garg $A D$, Dudek $A M$, Ferreira $G B$, Verfaillie $T$, Vandenabeele $P$, Krysko DV, Mathieu C, Agostinis $P$. ROS-induced autophagy in cancer cells assists in evasion from determinants of immunogenic cell death. Autophagy 2013; 9: 1292-1307.

24. Panzarini E, Inguscio V, Dini L. Timing the multiple cell death pathways initiated by Rose Bengal acetate photodynamic therapy. Cell Death Dis 2011; 2: e169.

25. Dini L, Inguscio V, Tenuzzo B, Panzarini E. Rose bengal acetate photodynamic therapy-induced autophagy. Cancer Biol Ther 2010; 10: 1048-1055.

26. Chen Y, Huang WP, Yang YC, Lin CP, Chen SH, Hsu ML, Tseng YJ, Shieh HR, Chen YY, Lee JJ. Platonin induces autophagy-associated cell death in human leukemia cells. Autophagy 2009; 5: 173-183.

27. Xue LY, Chiu SM, Azizuddin K, Joseph S, Oleinick NL. The death of human cancer cells following photodynamic therapy: apoptosis competence is necessary for Bcl-2 protection but not for induction of autophagy. Photochem Photobiol 2007; 83: 1016-1023.

28. Sasnauskiene A, Kadziauskas J, Vezelyte N, Jonusiene $V$, Kirveliene V. Apoptosis, autophagy and cell cycle arrest following photodamage to mitochondrial interior. Apoptosis 2009; 14: 276-286. 
29. Kessel D, Arroyo AS. Apoptotic and autophagic responses to Bcl-2 inhibition and photodamage. Photoch Photobio Sci 2007; 6: 1290-1295.

30. Francois A, Marchal S, Guillemin F, Bezdetnaya $L$. mTHPC-based photodynamic therapy induction of autophagy and apoptosis in cultured cells in relation to mitochondria and endoplasmic reticulum stress. Int $\mathrm{J}$ Oncol 2011; 39: 1537-1543.

31. Wang W, Moriyama LT, Bagnato VS. Photodynamic therapy induced vascular damage: an overview of experimental PDT. Laser Phys Lett 2013; 10: 023001.

32. Wang H, Dong C, Zhao P, Wang S, Liu Z, Chang J. Lipid coated upconverting nanoparticles as NIR remote controlled transducer for simultaneous photodynamic therapy and cell imaging. Int J Pharmacol 2013; 466 : 307-313.

33. Chernyak BV, lzyumov DS, Lyamzaev KG, Pashkovskaya AA, Pletjushkina OY, Antonenko YN,
Sakharov DV, Wirtz KW, Skulachev VP. Production of reactive oxygen species in mitochondria of HeLa cells under oxidative stress. Biochim Biophys Acta 2006; 1757: 525-534.

34. Buytaert E, Dewaele M, Agostinis P. Molecular effectors of multiple cell death pathways initiated by photodynamic therapy. Biochim Biophys Acta 2007; 1776: 86-107.

35. Krestyn E, Kolarova $H$, Bajgar $R$, Tomankova $K$. Photodynamic properties of ZnTPPS(4), CIAIPCS(2) and ALA in human melanoma G361 cells. Toxicol in Vitro 2010; 24: 286-291.

36. Du L, Jiang N, Wang G, Chu Y, Lin W, Qian J, Zhang Y, Zheng J, Chen G. Autophagy inhibition sensitizes bladder cancer cells to the photodynamic effects of the novel photosensitizer chlorophyllin e4. J Photochem Photobiol B 2014; 133: 1-10. 